\title{
Does Chitosan Improve the Lumen of the Heart Arteries in Diabetes Mellitus?
}

\author{
Herin Setianingsih, Wahyu Prasasti Mutiadesi, Peppy Nawangsasi
}

\begin{abstract}
Diabetes mellitus is known as a metabolic disease characterized by hyperglycemia caused by impaired insulin secretion, insulin action, or both and impaired metabolism of carbohydrates, fats and proteins. Diabetic angiopathy is a chronic complication of diabetes mellitus occurs in essential blood vessels throughout the body, started by endothelial dysfunction of vascular endothelial. Chitosan increases cardiac performance due to amino polysaccharide molecules. This study aims to determine the use of chitosan as adjunctive therapy for diabetes mellitus by looking at the arterial lumen of the heart arteries. Histopathological changes were observed by seeing the blood that filled the lumen of the heart arteries. Sixteen white rats divided into two groups: group 1 as treatment groups were injected by streptozotocin and group 2 as a treatment group was injected streptozotocin and giving chitosan. Data collection of coronary arteries was performed with a score of $3>75 \%$, between $25 \%-75 \%$ given two scores, and $<25 \%$ were given rating 1 . The results of paired t-test can be significant value between the observation of the blood that filled the lumen of the blood vessel of the heart $(p:<0,005)$ indicating there is a significant difference between diabetic rats with streptozotocin that given chitosan compare with diabetic rats were not given chitosan. It can be concluded that chitosan as adjunctive therapy for diabetes mellitus can improve the lumen of the heart arteries.
\end{abstract}

Keywords: chitosan, diabetes mellitus, lumen of the heart arteries.

\section{INTRODUCTION}

Diabetes mellitus is known as a metabolic disease characterized by hyperglycemia caused by impaired insulin secretion, insulin action, or both and impaired metabolism of carbohydrates, fats and proteins (1).

In Indonesia, people with diabetes were predicted from the amount of 2.5 million in 1994 to five million in 2010 (1) and Indonesia is the country with the fourth highest number of people with diabetes in the world (WHO). The death rate due to diabetes ranks the fifth worldwide, so many various therapies of natural and antidiabetic drugs are combined to overcome this disease although they have side effects. However, there are many natural therapies that do not have any side effects. One of them is chitosan, therefore it is necessary to try out the therapy in model animal that suffer from diabetes mellitus. Using streptozotocin (STZ) with low dose $(60 \mathrm{mg} / \mathrm{kgBW})$ was able to damage the cells of the pancreas, cause degranulation and decrease insulin secretion(2) .

Many diabetes mellitus therapy do not only used oral antidiabetic drugs. Administration of chitosan as an

\footnotetext{
Revised Manuscript Received on January 2, 2020.

* Correspondence Author

Herin Setianingsih*, Department of Anatomy, Medical Faculty, Universitas Hang Tuah Surabaya Indonesia. Email: herin.setianingsih@hangtuah.ac.id

Wahyu Prasasti Mutiadesi, Department of Anatomy, Medical Faculty, Universitas Hang Tuah Surabaya Indonesia. Email: wahyu.prasasti@hangtuah.ac.id

Peppy Nawangsasi, Department of Anatomy, Medical Faculty, Universitas Hang Tuah Surabaya Indonesia. Email: peppy.nawangsasi@hangtuah.ac.id
}

adjunctive therapy has ever been investigated (3). Besides, chitosan is a natural supplement because it comes from an extracted marine product, so that it is safer (4). Therapy in diabetic is a very common problem, requiring a high adherence of patients, complex, and require high cost. Overall, the direct health care costs in the management of diabetes mellitus and its complications are between $2.5 \%$ to $15 \%$ of the annual health budget of a country, and the cost of lost productivity due to diabetes-related as five times greater than direct medical costs (5) .

Patients with diabetes mellitus are at risk of coronary heart disease (CHD) and cerebrovascular disease 2 times larger, 50 times more likely to suffer from ulcer/gangrene, 7 times more likely to suffer from terminal renal failure and 25 times more likely to suffer blindness due to retinal damage than patients without diabetes mellitus. Chronic complications of diabetes mellitus essentially occur in all blood vessels throughout the body (diabetic angiopathy). Endothelial dysfunction is an early event that facilitates the occurrence of atherosclerosis which leads the occurence of macroangiopathic complication and microangiopathic diabetes (6).

Using chitosan as an adjunctive therapy for diabetes mellitus will provide a different histopathologic to the cells of the heart and blood vessels of rats streptozotocin-induced diabetic rats which are given an additional therapy with chitosan compared with the ones without chitosan therapy.

\section{MATERIALS AND METHODS}

The study was conducted at the Laboratory of Biochemistry Faculty of Medicine, Universitas Hang Tuah Surabaya, for 6 months. Laboratory tests were conducted in Prodia Clinical Laboratory, Surabaya and histopathological examination were in Anatomical Pathology Laboratory navy hospital RSPAL dr Ramelan Surabaya.

Rats were adapted for 2 weeks. Sixteen tail rats were divided into 2 treatment groups. The first group of rats that were only injected with a single dose of $50 \mathrm{mg} / \mathrm{kgBW}$ of streptozotocyn. the second group of rats that were injected with $50 \mathrm{mg} / \mathrm{kgBW}$ streptozotocyn single dose were then given $500 \mathrm{mg} /$ day chitosan therapy for 12 days.

This research used an experimental method. The resulted data were analyzed using a paired-sample t test with SPSS for mac program with a $95 \%$ significance level.

\section{RESULT AND DISCUSSION}

After the samples were randomly grouped according to the inclusion and exclusion criteria so that each group consisted of eight male Wistar rats as the sample. The study was conducted for 24 days and the data obtained by measurement of blood glucose of each rat experiments The results of the measurement of blood glucose level were used as an indicator

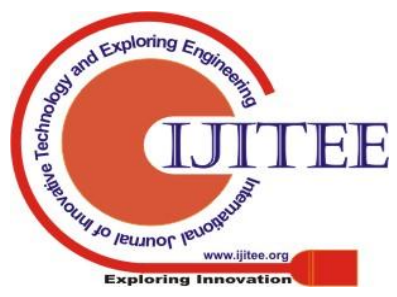


of diabetes mellitus in rats which showed an average increase of diabetes after being treated with streptozotocin injection $50 \mathrm{mg} / \mathrm{KGB}$, the blood sugar level close to normal is was decreased in diabetic rats that received chitosan treatment $500 \mathrm{mg} /$ day for 12 days.

The increased blood glucose level in streptozotocin administration can be caused by two processes, namely the formation of free radicals and the destruction of pancreatic beta cells that produce insulin function. Streptozotocin toxic action on beta cells is initiated by free radicals formed by redox reactions (Watskin, 2008). The purpose of this study was to determine whether there is a change of heart histology on providing chitosan therapy, especially those related to the heart's blood vessels and heart muscle figure sets in general. The samples used were 24 white rats which were then divided into 3 groups.

The first group consisted of 8 rats as the control group, the second group as the treatment group was made diabetic with streptozotocin without chitosan and the third treatment group was made diabetic with streptozotocin administration by providing chitosan. At the end of treatment all rats were decapitated and took out heart organ was made slice preparations, each preparation read with magnification 400X of the microscope 5 fields of view. The assessment was observed by looking at the histological feature of blood that filled the lumen of the blood vessels of the heart. Histological feature data collection of vessel coronary arteries was performed by giving a score of " 3 " if the blood amount was > $75 \%$, between $25 \%-75 \%$ was given a score of "2" and $<25$ was given a score of " 1 ".

The results of this study showed that diabetic rats that were given chitosan treatment had more blood that filled the heart's blood vessels compared to the control group and the treatment group without chitosan therapy. However, the test results have shown that the administration of chitosan increased vascularization of the heart. Related to the results of this study, further study needs to be done to know the effect of increased vascularization of the heart with chitosan therapy with larger doses and longer administration duration. Research can also be done by looking at the histological picture of the organs other, then the heart. Therefore it can be known whether this effect of increased vascularization only occurs at a contractedly functional organ, or the whole organ, and at what dose of chitosan effectively administered and how long is it ideal to be administered.

The primary data obtained by observing the histological figures of the blood amount that filled the lumen of blood vessels in the heart and then did a test for normality of data distribution using the Kolmogorov Smirnov test and showed that the data was normally distributed ( $p>0.05)$. Because the data were normally distributed and data showed the ratio data, testing data using parametric statistics of paired sample t-test with SPSS for mac. The results of the statistical test of the paired-sample t-test can have a significant value in the observed amount of blood that filled the lumen of blood vessels in rats with diabetic rats. While the results of statistical tests between the amount of blood that filled the lumen of blood vessels in diabetic rats that were not given chitosan and diabetic rats fed with chitosan were not significant ( $p>0.05)$, it means, it was indicated no significant difference between diabetic rats fed with chitosan and diabetic rats without chitosan.

The effect of chitosan on endothelial and vascular due to its characteristics as an antioxidant that can improve the quality of endothelial, blood vessels and smoothen blood circulation The results which were not significant in this study may be due, to less time chitosan administration, since chitosan is not an antidiabetic drug but it is an additional supplement of dietary fiber (fiber that can be eaten) and can lower blood glucose levels by two mechanisms, namely chitosan (chitooligosakarida) which has alkaline substances and can raise the $\mathrm{pH}$ and the $\mathrm{pH}$ of the body fluids and is sensitive to insulin. Chitosan can regulate the function of the endocrine system and makes insulin secretion to normal. Moreover that chitosan can stimulate the proliferation of beta cells of pancreas damage and repair it (2). Other related researches have also been conducted about blood vessels but by measuring the lumen diameter of blood vessels (8).

The theory that is closely related to this research is if the lumen of blood vessels filled with more blood than the lumen of blood vessels filled with less blood can show that the lumen that is filled with more blood vessels means that atherogenesis does not occur or there is less atherogenesis. if the atherogenesis process occurs in the lumen of the blood vessels, of course, there will be a narrowing of the lumen diameter of the blood vessels so that the histopathological picture seen by observing the contents of the lumen can also show the results of a lower blood percentage compared to healthy blood vessels and atherogenesis does not occur.

Vascular lumen repair is a dynamic process that molecularly involves several pathways including VEGF (vascular endothelial group factor) Vascular endothelial cadherin (VE-cadherin) and several other pathways that can still be further investigated

Chitosan administration to blood vessel endothelium will trigger an increase in vascular endothelial-cadherin expression so that it can accelerate the formation of collagen (9).

\section{CONCLUSION}

The administration of chitosan to diabetic mellitus rats showed improvement in microscopic features of the lumen of the heart arteries.

\section{ACKNOWLEDGMENT}

The author wish to thank the Hang Tuah University of Medical Science for its financial support.

\section{REFERENCES}

1. World Health Organization. Definition, Diagnosis and Classification of Diabetes Mellitus and its Complications Part 1: Diagnosis and Classification of. World Health [Internet]. 1999;15(7):539-53. Available from: http://www.ncbi.nlm.nih.gov/pubmed/9686693

2. Najafikhah N, Hashemi-Najafabadi S, Zahediasl S, Nabavimanesh MM, Farrokhfall K. Normal insulin secretion from immune-protected islets of langerhans by pegylation and encapsulation in the alginate-chitosan-PEG. Iran J Biotechnol. 2018;16(4):258-63.

3. Wang $\mathrm{Q}$, Jin $\mathrm{T}$. The role of insulin signaling in the development of $\beta$-cell dysfunction and diabetes. Islets. 2009;1(2):95-101.

4. de Alvarenga ES. Characterization and Properties of Chitosan. Biotechnol Biopolym. 2011;(May).

5. Kumar AA, Reddy V, Parveen S. Evaluation of Medication Adherence in Type-2 Dm Patients in a Tertiary Care Evaluation of Medication Adherence in Type-2 Dm Patients in a Tertiary Care Teaching Hospital. 2019;(May).

6. Sargowo D. Disfungsi Endotel. Malang: UB Press; 2015

7. Kerch G. The potential of chitosan and its derivatives in prevention and treatment of Age-related diseases. Mar 
Drugs. 2015;13(4):2158-82.

8. Ruan L, Chen W, Srinivasan SR, Sun M, Wang H, Toprak A, et al. Correlates of common carotid artery lumen diameter in black and white younger adults: The bogalusa heart study. Stroke. 2009;40(3):702-7.

9. Deng C, Zhang P, Vulesevic B, Kuraitis D, Li F, Yang AF, et al. A collagen-chitosan hydrogel for endothelial differentiation and angiogenesis. Tissue Eng - Part A. 2010;16(10):3099-109.

\section{AUTHORS PROFILE}

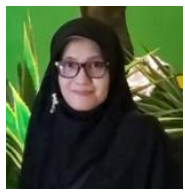

Dr. Herin Setianingsih, dr.,M.Kes, PA working as lectures and researcher of Universitas Hang Tuah Surabaya Indonesia. She holds his Master Degree in Basic medical Program from Universitas Airlangga Surabaya Indonesia. Whereas she had been awarded his Doctoral program from Universitas Airlangga Surabaya Indonesia. Being an academician and researcher she has more than 17 Years of Teaching Experience and Research experience in the field of anatomy, histology and molecular biology. She is also working as supervisor of Integrated Laboratory of Universitas Hang Tuah Surabaya Indonesia. She also the head of the research institute and community services. The research Interest: Anti-diabetic, Hyperlipidemia, Cardiovascular, Anti-inflammatory, Hyperbaric Oxygen Therapy and all about molecular biology. Member of Indonesian Association of Anatomist (IAA) - International Federation of Asssociations of Anatomists (IFAA).

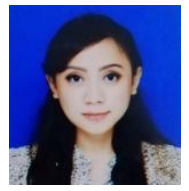

Wahyu Prasasti Mutiadesi, MD, M. Biomed.

Presently working as staff and lecture in the Departement of Anatomy at Faculty of Medicine, Hang Tuah University in Indonesia. Has completed as Doctor of Medical (MD) from Faculty of Medicine, Hang Tuah University in Indonesia in the year 2012 and Master of Biomedicine (M. Biomed.) from Biomedical Sciences, Faculty of Medicine, Universitas Indonesia in the year 2017. Member of Indonesian Association of Anatomist (IAA) - International Federation of Asssociations of Anatomists (IFAA). Currently working in the research area of anatomy, biomedical sciences, biomechanics, and kinesiology.

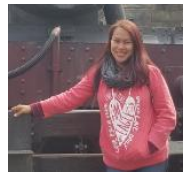

Peppy Nawangsasi, $\mathrm{dr}$

Academic Background: Graduated from Faculty of Medicine, Hang Tuah University Indonesia, Bachelor degree. Studying master degree Universitas Airlangga Surabaya Indonesia.

Work History : Staff and Lecture in the Departement of Anatomy at Faculty of Medicine, Hang Tuah University Indonesia. Member of Indonesian Association of Anatomist (IAA) - International Federation of Asssociations of Anatomists (IFAA). Currently working in the research area of anatomy, physical anthropology, and kinesiology. 